\title{
Identification and Analysis of Human Errors in the Maintenance Activities of Molecular Sieve Replacement in the Dehydration Unit of Gas Refineries Using Predictive Human Error Analysis Method
}

\author{
Hamid Reza Pourimani ${ }^{1, *}$, Mostafa Abbasi ${ }^{2}$ \\ ${ }^{1}$ MSc Student in Industrial Safety, Tabnak Lamerd Institute of Higher Education, Lamerd, Iran \\ ${ }^{2}$ Assistant Professor, Industrial Safety Department, Tabnak Lamerd Institute of Higher Education, Lamerd, Iran
}

* Corresponding Author: Hamid Reza Pourimani, Tabnak Lamerd Institute of Higher Education, Lamerd, Iran. Email: Hamid_poorimani@yahoo.com

\begin{abstract}
Received: $13 / 06 / 2018$

Accepted: 20/09/2018

How to Cite this Article: Pourimani HR, Abbasi M. Identification and Analysis of Human Errors in the Maintenance Activities of Molecular Sieve Replacement in the Dehydration Unit of Gas Refineries Using Predictive Human Error Analysis Method. $J$ Occup Hyg Eng. 2018; 5(2): 5564. DOI: 10.21859 /johe-5.2.55

Background and Objective: Incidental events due to human error in the maintenance activities of molecular sieve replacement in the dehydration unit of gas refineries indicate the inadequate effectiveness of the techniques available to identify human errors. This study aimed to identify and analyze human errors in this maintenance activity using the predictive human error analysis (PHEA) technique and provide appropriate control strategies to prevent or reduce the consequences of identified errors.

Materials and Methods: In this study, all activities and tasks performed to achieve the main goals were identified using hierarchical task analysis (HTA) technique. Subsequently, possible types of human errors in each phase of the above processes were predicted and identified using the PHEA method and a series of guidance keywords.After determining the consequences of each error, appropriate control methods were also provided. Results: Out of 11 operations and 111 sub task occupations analyzed in the PHEA worksheets, a total of 337 errors were identified, of which 246, 13, 28, 33, and 17cases were regarded as action, checking, retrieval, information transfering and planning errors, respectively. The most significant identified errors were forgetting the task, doing the task incorrectly, incompletely, at the wrong time, making the right decision on the wrong option, and doing the task more or less than necessary.

Conclusion: According to the obtained results, it can be concluded that functional errors were the most prevalent type of errors. Theses results emphasize the necessity of using control strategies in terms of adequate and effective training for personnel, the preparation and modification of instructions, the monitoring of implementation of work and hardware changes.
\end{abstract}

Keywords: Human Error; HTA; Gas Refinery; Molecular Sieves; PHEA 
dof: $10.21859 /$ johe- 5.2 .55

\title{
شناسايى و تجزيه و تحليل خطاهاى انسانى در فعاليت تعويض غربالهاى مولكولى واحد نمزذايى يالايشكاه كازى با استفاده از روش Predictive Human Error ) PHEA
}

(Analysis

\author{
حميدرضا يورايمانى اء*، مصطفى عباسى \\ ' دانشجوى كارشناسى ارشد ايمنى صنعتى، موسسه آموزش عالى تابناك لامرد، لامرد، ايران

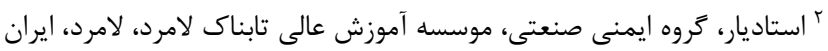 \\ * نويسنده مسئول: حميدرضا يورايمانى، موسسه آموزش عالى تابناك لامرد، لامرد، ايران. \\ ايميل:Hamid_poorimani@yahoo.com
}

\begin{abstract}
جكيده
سابقه و هدف: حوادث رخداده در فعاليت تعميراتى تعويض غربالهاى مولكولى واحد نهزدايى پالايشگاههاى

تاريخ دريافت مقاله: זץ/ץ •/

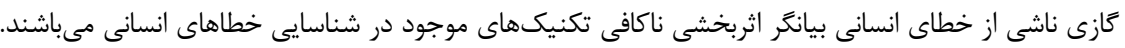

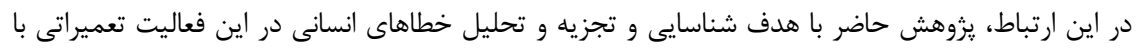
استفاده از روش تجزيه و تحليل خطاى انسانى يِيشبينىشده (PHEA: Predictive Human Error Analysis)

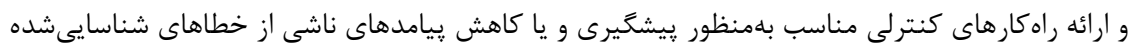

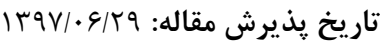
تمامى حقوق نشر براى دانشكاه علوم يزشكى همدان محفوظ است.

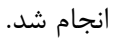
مواد و روشها: در يروهش حاضر تمامى فعاليت ها و وظايفى كه براى دستيابى به اهداف اصلى انجام مىشوند، با استفاده از روش تجزيه و تحليل وظيفه شغلى سلسلهمراتبى Hierarchical Task Analysis) HTA

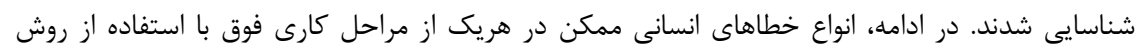
PHEA

$$
\text { رافهاى كنترلى مناسب ارائه كشت. }
$$

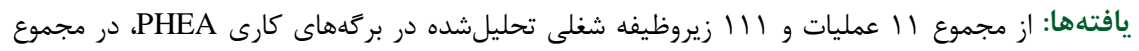

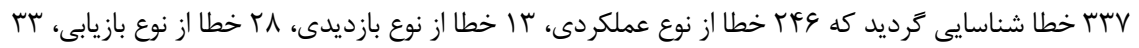

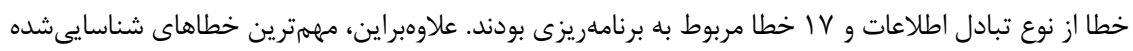

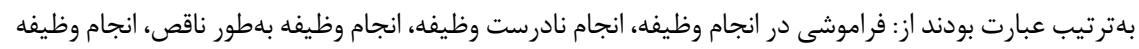

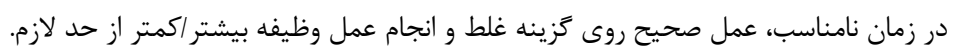

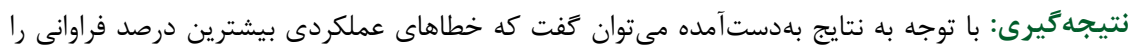

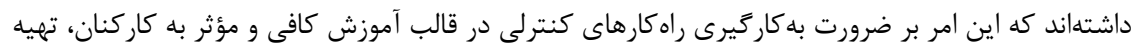

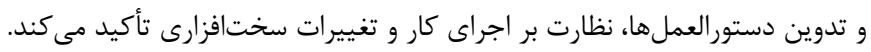

وازَّان كليدى: پالايشًاه كَازى؛ خطاى انسانى؛ غربالهاى مولكولى؛ PHEA HTA؛

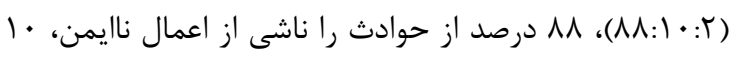

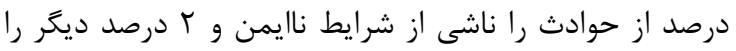

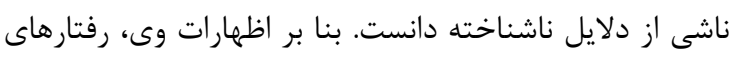

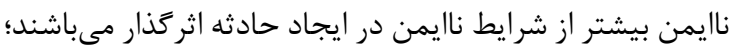

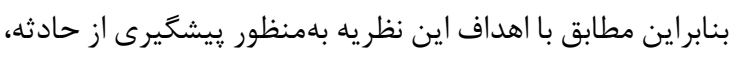

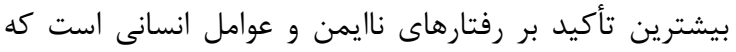

مقلدمه انسان بهعنوان طراح، برنامهريز و كاربر سيستم، نقش بسيار

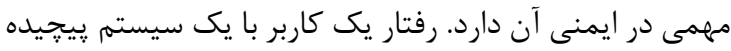

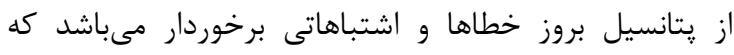

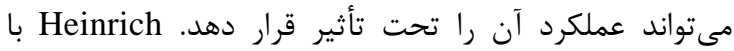

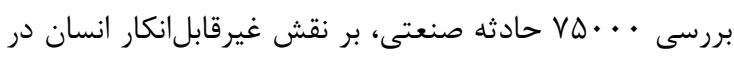

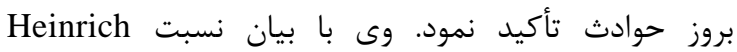


مولكولى برج اقدام نمود كه انجام اين عمليات يرريسك بوده

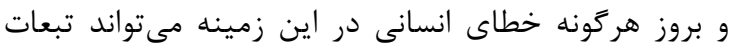

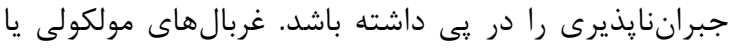

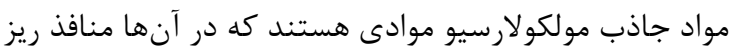

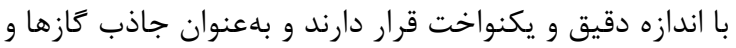

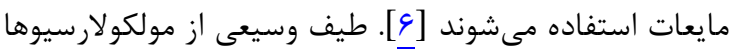

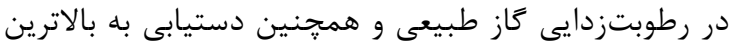

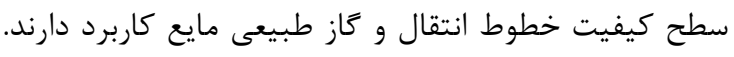

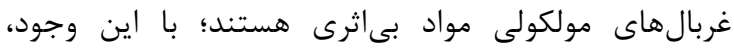

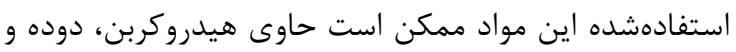

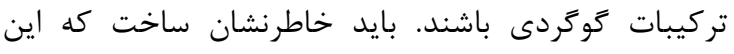

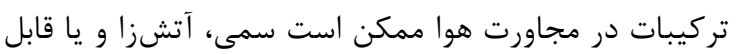

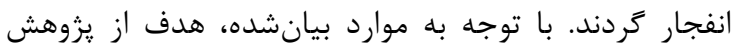
حاضر شناسايى و تجزيه و تحليل خطاهاى انسانى در فعاليت بردي

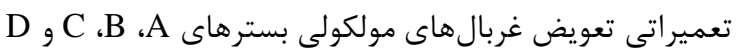

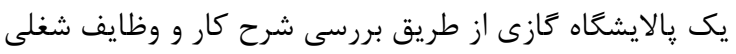

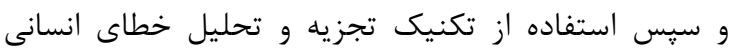

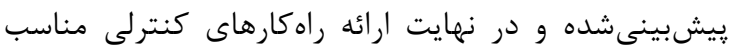

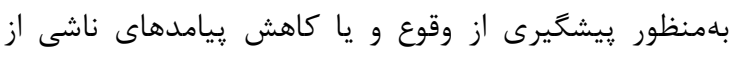
خطاهاى شناسايى شده مى باشد.

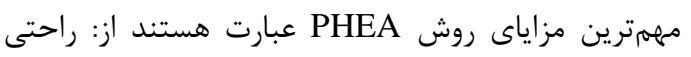

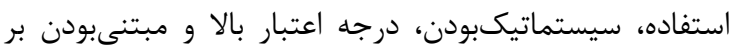

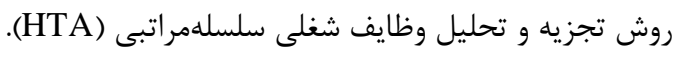

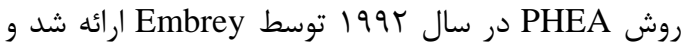

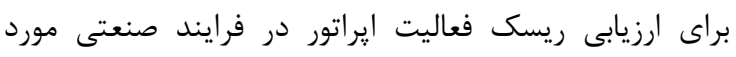

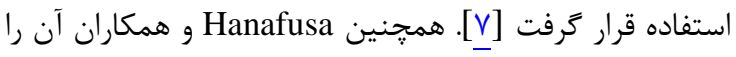

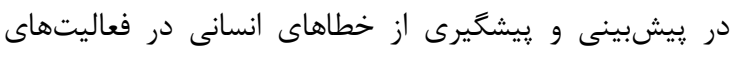

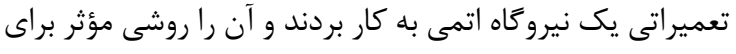

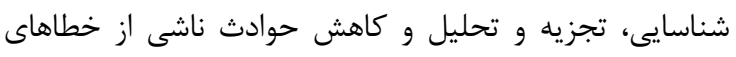
انسانى در فعاليتهاى تعميراتى، صنايع شيميايى و هوايى تهائ إنى توصيف كردند [1].] Stanton و نيز بهمنظور شناسايى قابليت اطمينان

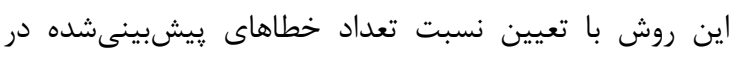

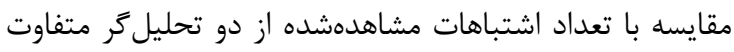

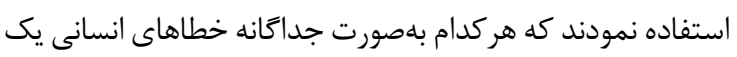

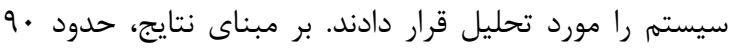

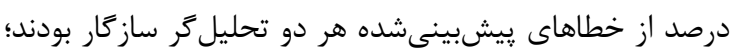

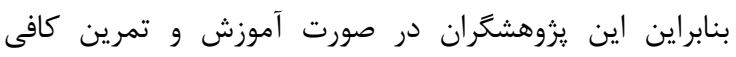
تحليل خطاى كاربر دانستند [V] روش PHEA ييشتر توسط جهانگيرى و همكاران بلمنظور

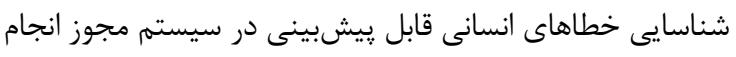

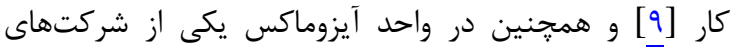

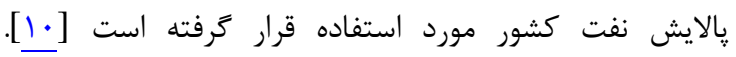

مىتواند منجر به حادثه شوند [1]. در يزوهشى در ارتباط با

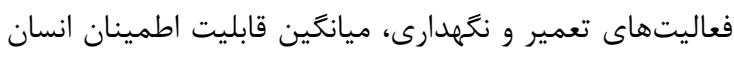

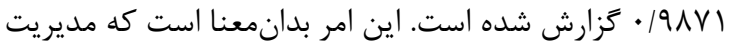

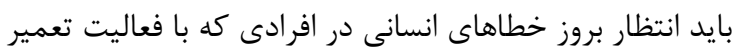

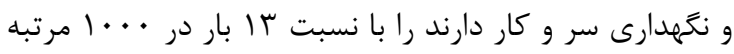

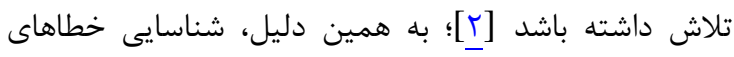

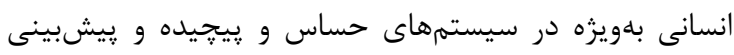

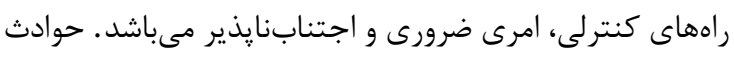

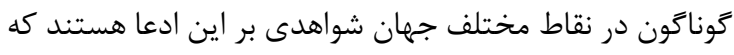

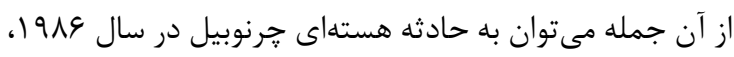

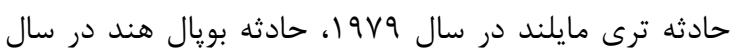

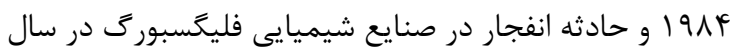

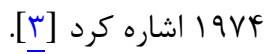

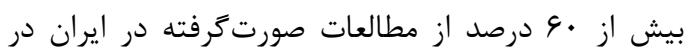

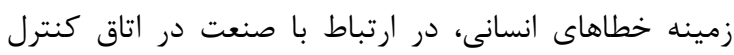

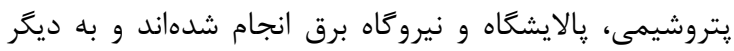

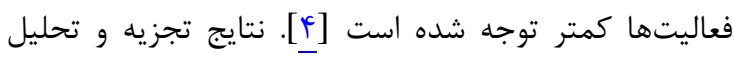

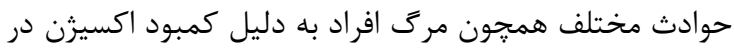

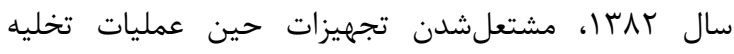

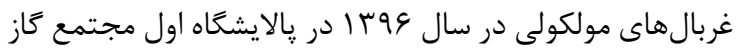

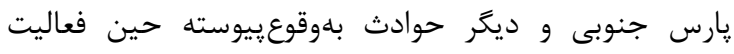

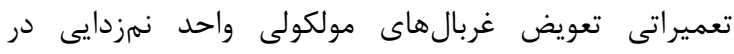

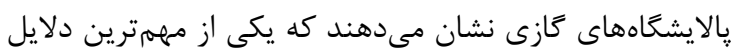

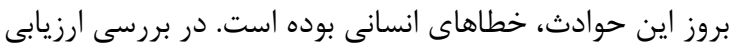

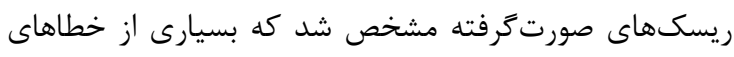

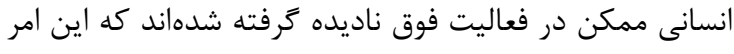

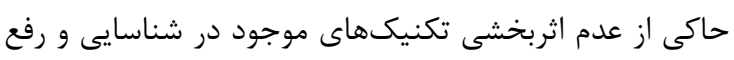
خطاهاى انسانى مى باشد.

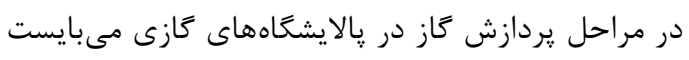

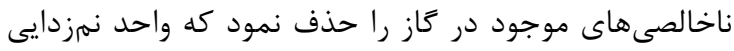

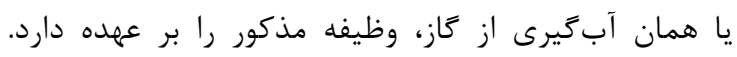

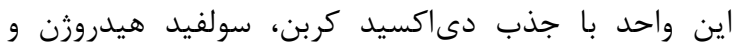

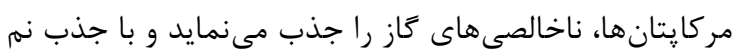

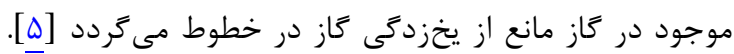

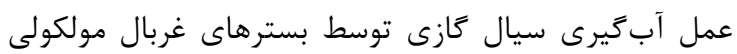

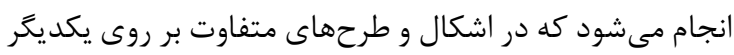

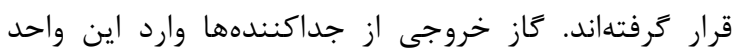

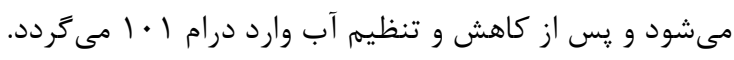

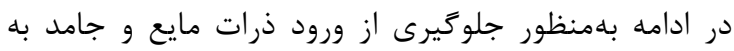

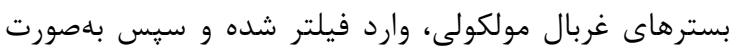

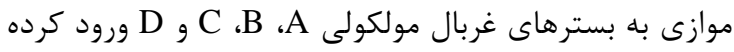

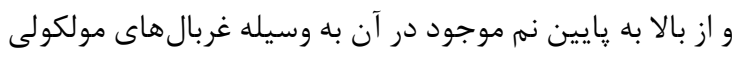

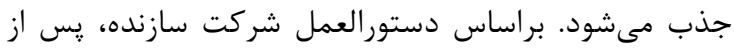

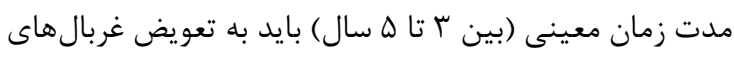


جدول r: جكليست شناسايى خطاهاى انسانى در روش PHEA [0

\begin{tabular}{|c|c|c|}
\hline توصيف خطا & شناسه خطا & نوع خطا \\
\hline بازديد فراموش مىشود & $\mathrm{C} 1$ & \multirow{5}{*}{$\begin{array}{r}\text { Checking ( كلمات راهنماى خطاهاى مربوط به بازديد } \\
\text { (Errors }\end{array}$} \\
\hline بازديد بلطور ناقص انجام مىشود & $\mathrm{C} 2$ & \\
\hline بازديد در مورد يك كزينه غلط انجام مىشود & C3 & \\
\hline بازديد اشتباه در مورد گزينه صحيح انجام مىشود & $\mathrm{C} 4$ & \\
\hline بازديد در زمان نامناسب صورت مى كيرد & C5 & \\
\hline عمل مورد نظر خيلى سريع/آهسته انجام مىشود & A1 & \multirow{9}{*}{ كلمات راهنماى خطاهاى عملكردى (Action Errors) } \\
\hline عمل مورد نظر در زمان نامناسب انجام مىشود & A2 & \\
\hline عمل مورد نظر در جهت اشتباه انجام مىشود & A3 & \\
\hline عمل مورد نظر بيشتر از حد/كمتر از حد انجام مىشود & A4 & \\
\hline عمل مورد نظر بهصورت نادرست انجام مىشود & A5 & \\
\hline عمل صحيح در مورد يك گزينه غلط انجام مىشود & A6 & \\
\hline عمل اشتباه در مورد يك گزينه صحيح انجام مىشود & A7 & \\
\hline عمل مورد نظر فراموش مىشود & A8 & \\
\hline عمل مورد نظر بهطور ناقص انجام مىشود & A9 & \\
\hline 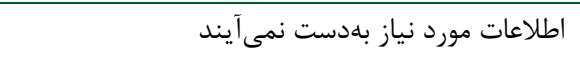 & $\mathrm{R} 1$ & \multirow{3}{*}{ كلمات راهنماى خطاهاى بازيابى (Retrieval Errors) } \\
\hline اطلاعات مورد نياز بهصورت اشتباه بهدست مىآيند & $\mathrm{R} 2$ & \\
\hline اطلاعات مورد نياز بهطور ناقص بهدست مى آيند & R3 & \\
\hline تبادل اطلاعات صورت نمى & I1 & \multirow{3}{*}{$\begin{array}{l}\text { كلمات راهنماى خطاهاى مربوط به تبادل اطلاعات } \\
\text { (Information Communication Errors) }\end{array}$} \\
\hline اطلاعات اشتباه تبادل مىشوند & I2 & \\
\hline تبادل اطلاعات بهطور ناقص صورت مى گيرد & I3 & \\
\hline يِششرطهاى برنامه ناديده گرفته مىشوند & $\mathrm{P} 1$ & \multirow{4}{*}{ كلمات راهنماى خطاهاى برنامهريزى (Planning Errors) } \\
\hline برنامهريزى اشتباه به اجرا در آمده است & $\mathrm{P} 2$ & \\
\hline برنامه صحيح بوده؛ اما درست اجرا نشده است & P3 & \\
\hline برنامهريزى خيلى دير اخيلى زود به اجرا درآمده است & P4 & \\
\hline انتخاب بين ززينههاى مختلف فراموش مىشود & $\mathrm{S} 1$ & \multirow{2}{*}{ 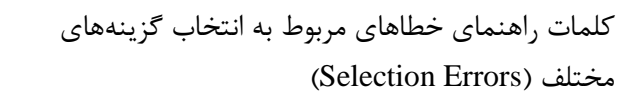 } \\
\hline كزينه مورد نظر به اشتباه انتخاب مىشود & $\mathrm{S} 2$ & \\
\hline
\end{tabular}

بايد خاطرنشان ساخت كه استراتثىهاى كاهش خطا در

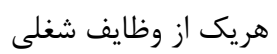

بلهور معمول در قالب آموزش، تدوين دستورالعمل، تغييرات

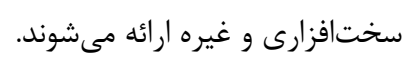

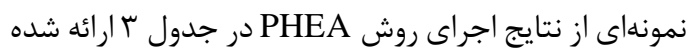

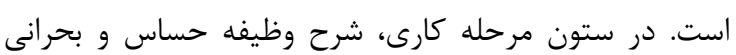

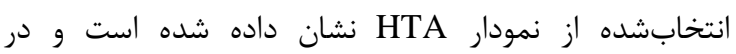

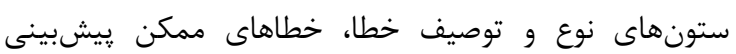
كرديده و شرح داده شدهاند. علاوهبراين، در ستون ريكاورى درى درى

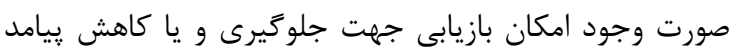

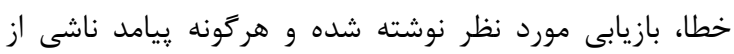

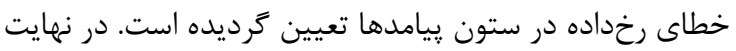

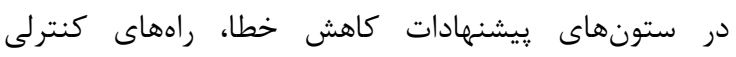

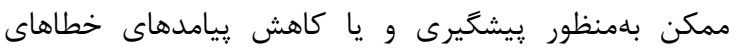

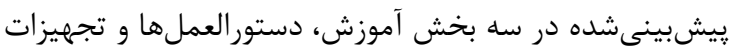
ارائه كرديدهاند.
نقص در دستورالعملهاى كارى و نظارت در بروز خطاها بحث مى گردد. تجزيه و تحليل پييامدهاى هر خطا: انجام اين مرحله نيازمند تحليل

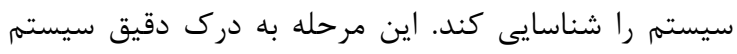

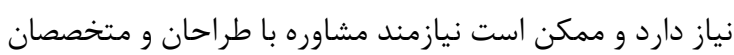

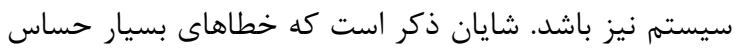
و بسيار محتمل بايد اولويت بالاترى نسبت به به ساير خدان خطاها داشته باشند.

\section{راهبردهاى كاهش و يا يِيشگيرى از بروز خطا:}

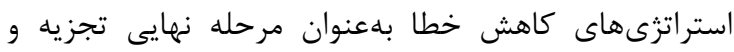

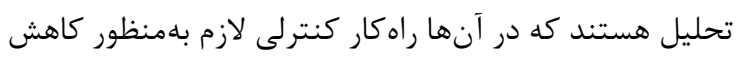

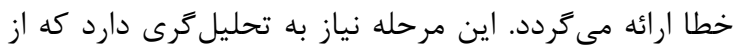

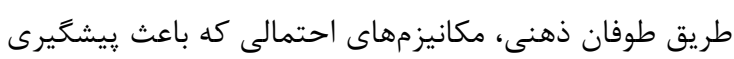

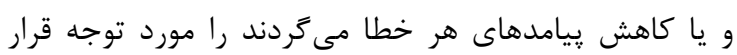


جدول با: نمونه بركه كارى PHEA بهمنظور فعاليت تعميراتى تعويض غربالهاى مولكولى واحد نمزدايى

\begin{tabular}{|c|c|c|c|c|}
\hline ي بيامد ناشى از خطا & مرحله بازيابى & توصيف خطا & خوعا & 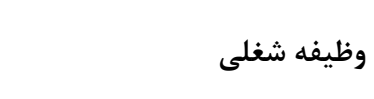 \\
\hline افزايش بيش از حد فشار و دما در تجهيزات & افزايش & $\begin{array}{c}\text { FT بطا در ارسال داده از (Fault Tolerance) } \\
\text { Board }\end{array}$ & $\mathrm{R} 2$ & 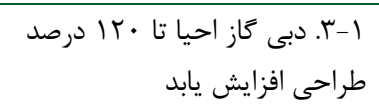 \\
\hline بروز تنش حرارتى در تجهيزات و آسيب به & بازيد مجدات & $\begin{array}{c}\text { كرمايش بيش از دماى طراحى افزايش يابد } \\
\text { افي }\end{array}$ & A4 & 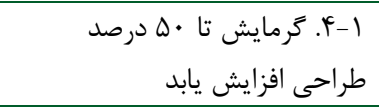 \\
\hline شوك الكتريكى و برق كرفتگى افراد (مرك) & 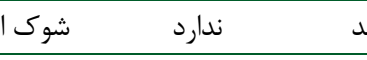 & تجهيزات ايزوله برقى نخردند & A8 & r. ايزوله برقى تجهيزات \\
\hline ورود كاز به برج و خفكَى افراد؛ خطر بروز & انجام آزمون كاز & ولو مورد نظر بهطور كامل ايزوله & A9 & ا -r. بستن ولوهاى ورودى \\
\hline 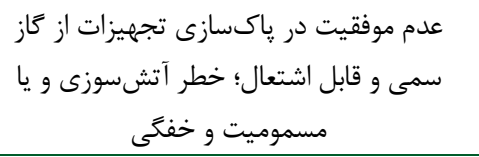 & سمى و و & فراموشى ايراتور در بازكردن مسير & A8 & r-F. بازكردن مسير نيتروزن \\
\hline 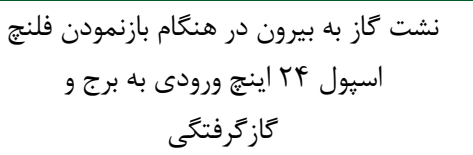 & نشت & اشكال در عملكرد دستگاه آزمون & $\mathrm{R} 2$ & 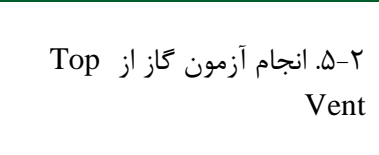 \\
\hline 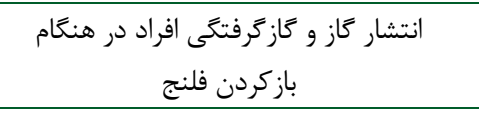 & 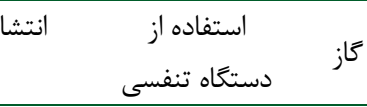 & بازشدن فلنج ييش از آزمون كاز & A2 & 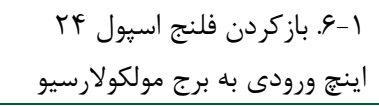 \\
\hline 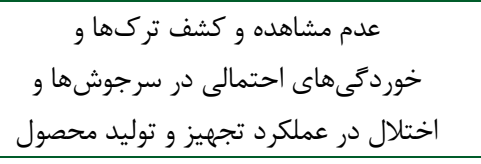 & خورد & بازديد و جك فراموش گردد & $\mathrm{C} 1$ & توسط افراد بخش بازئ نقاط جوشكارىشده فـ فنى \\
\hline \multicolumn{4}{|c|}{ راههاى كنترلى } & \multirow{2}{*}{ 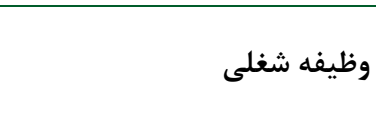 } \\
\hline تجهيزات & آموزش & دستور العملها & & \\
\hline نصب FT ثانويه در محل & 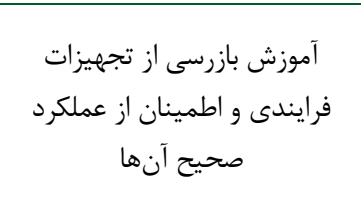 & \multicolumn{2}{|c|}{ 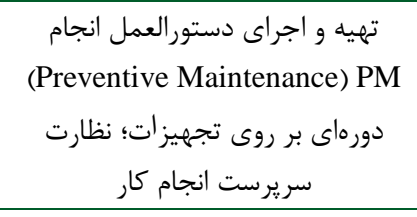 } & 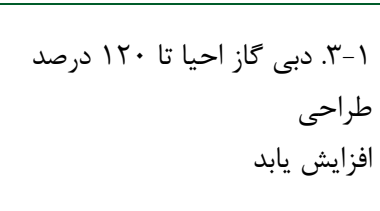 \\
\hline تصهيز آلارم افزايش دماى جهت آكاهى ايراتور & آموزش ايراتور در زمينه خطرات & 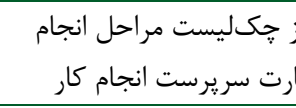 & 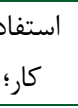 & 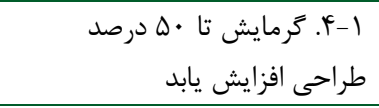 \\
\hline نصب جراغ نشانكر برقداربودن & 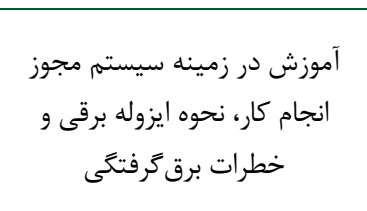 & 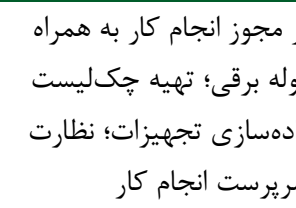 & 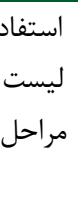 & r. ايزوله برقى تجهيزات \\
\hline Double Block Valves & 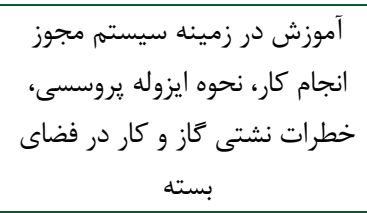 & ايزوله يروز انجام كار به همراه & 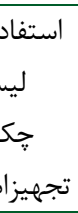 & ا I-r. بستن ولوهاى ورودى \\
\hline نصب برجسب خطر فضاى بسته & خطرات خنثى سازى تجهيزات و & 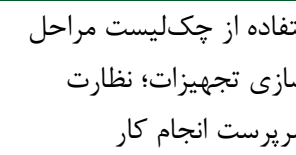 & تهيه آما & r-F- باز كردن مسير نيتروزن \\
\hline نصب برجسب كاليبره روى دستًاه & دآموزش آيراتور در زمينه كار با آزمون كاز و نخهدارى و & 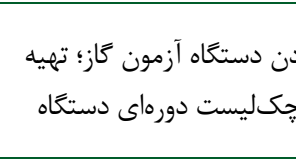 & 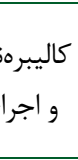 & 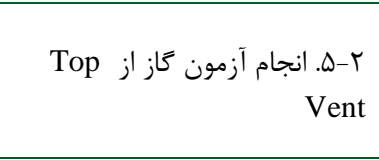 \\
\hline نصب علائم هشدار روى تجهيزات & 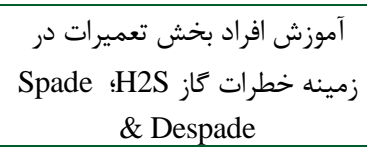 & دستور العمل انجام كار & & 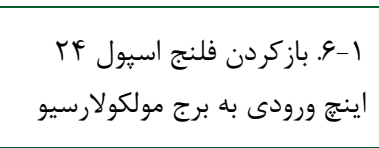 \\
\hline تهيه برجسب تأييديه فنى و & آموزش نحوه بازرسى تجهيزات & ليست بازرسى تجهيزات & & 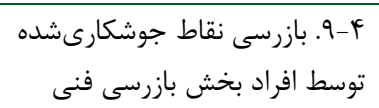 \\
\hline
\end{tabular}




\section{كافتهها}

r. خطاى فراموشى در انجام وظيفه شامل اع خطا: بهعنوان مثال اتر در مرحله كارى بستن ولوهاى ورودى درام 1 ـ ـ إيراتور

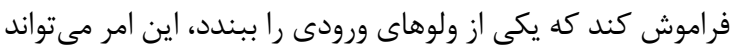

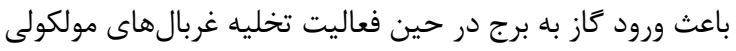

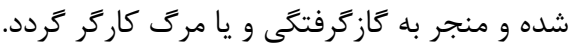

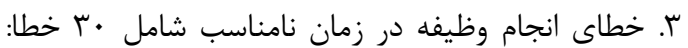

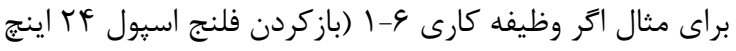

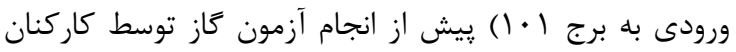

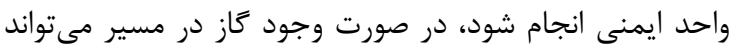

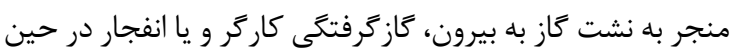
بازنمودن فلنج گَردد.

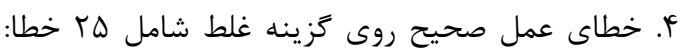

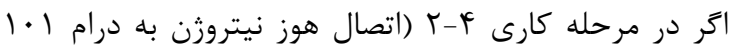

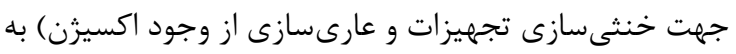

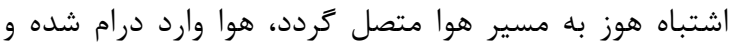

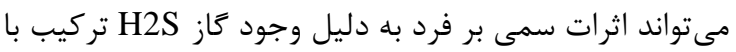

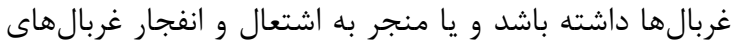
مولكولى گردد.

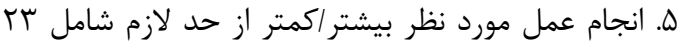

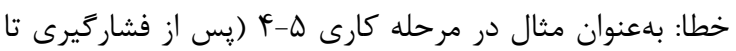

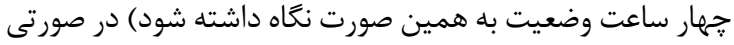
كه تجهيزات مطابق با برنامهريزى صورت

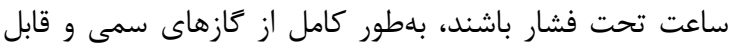

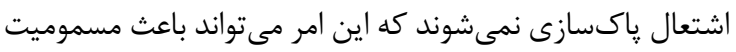

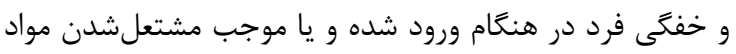
موجود در تجهيزات گرددد.

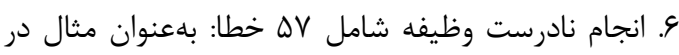

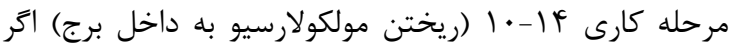

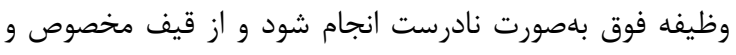
جورابى متصل به آن جهت انتقال و هدايت غربالها به به درستى ندرد

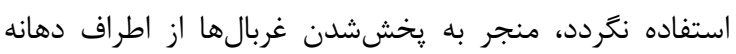

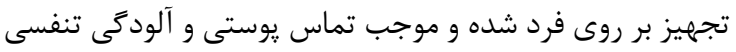
مى تردد.

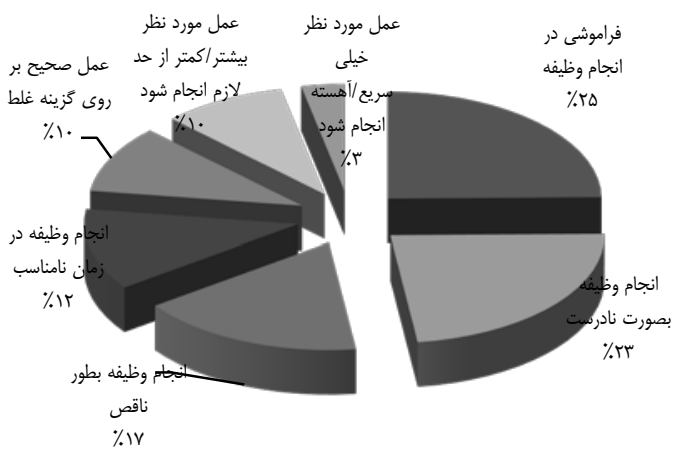

نمودار ب: خطاهاى عملكردى
يس از شناسايى كليه وظايف حساس و بحرانى با توجه به

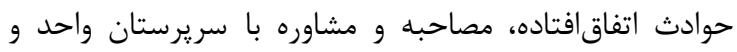

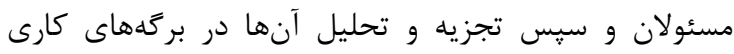
PHEA

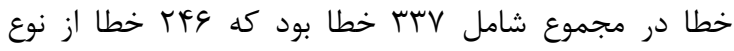

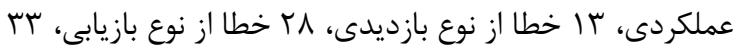

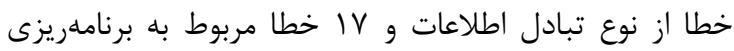

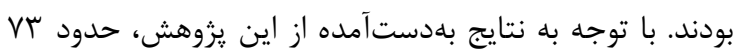

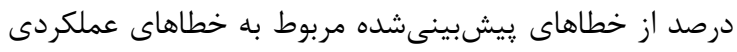

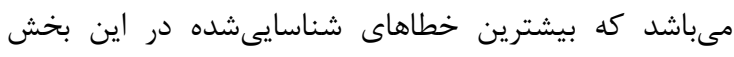

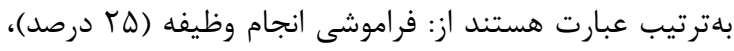

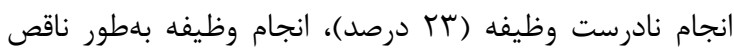

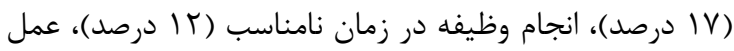

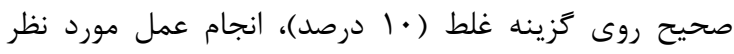

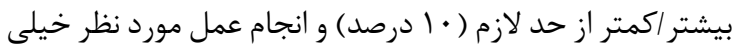

$$
\text { سريع/خيلى آهسته (ب درصد). }
$$

خطاهاى عملكردى: در مطالعه شناسايى خطاهاى انسانى

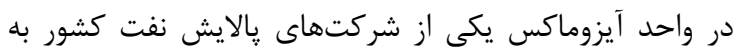

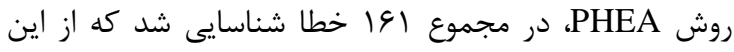

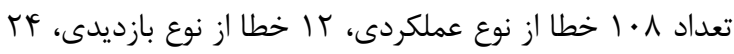

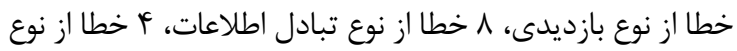

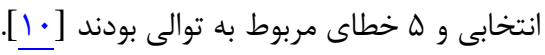

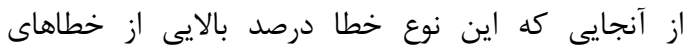

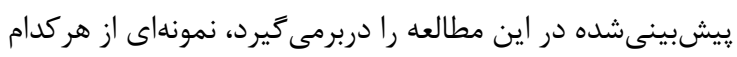
از خطاهاى شناسايىشده شرح داده مىشود.

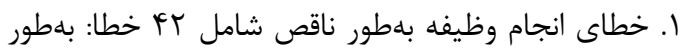

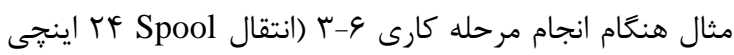

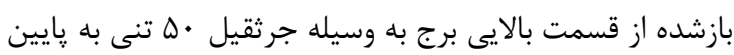

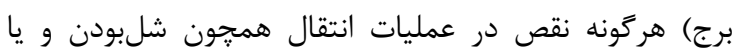

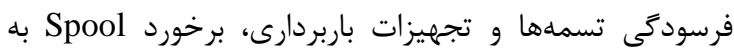

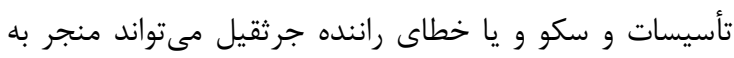

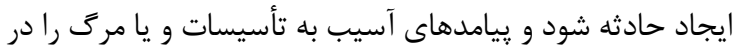
يى داشته باشد.

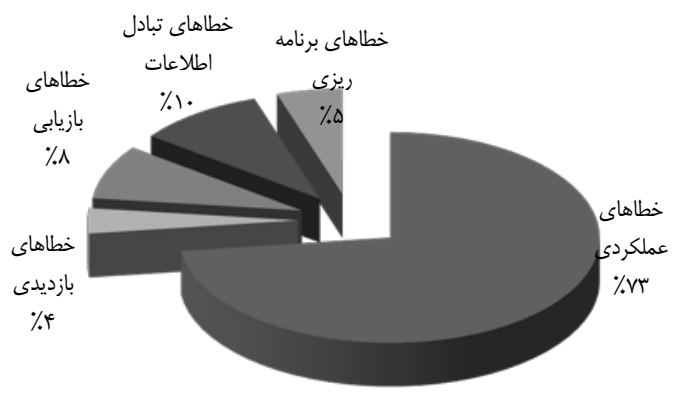

نمودار ا: كل خطاهاى پيشبينى شده 
خطاى بازديد: خطاهاى شناسايىشده از نوع بازديد حدود

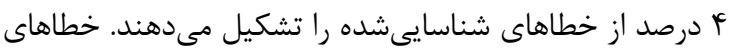

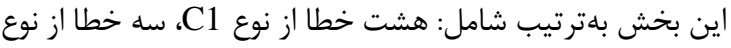

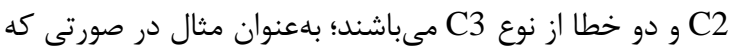
در مرحله كارى انجام آزمون كاز از

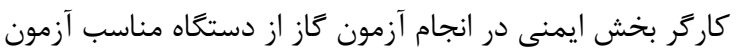

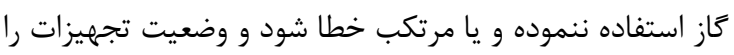

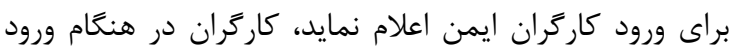

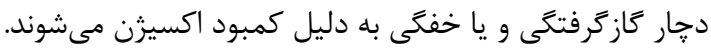

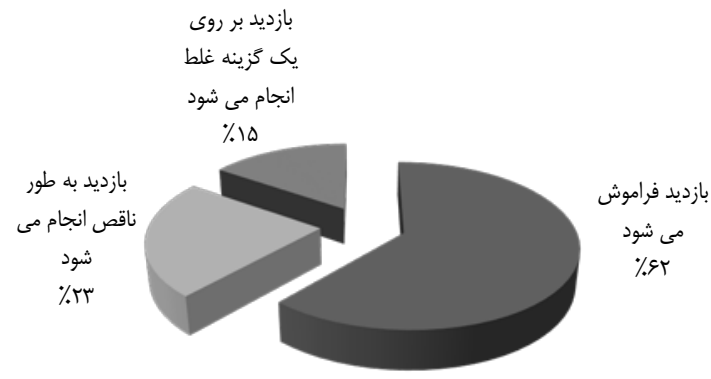

نمودار ه: خطاهاى بازديد

خطاى برنامهريزى: اين نوع خطا ها درصد از خطاهى

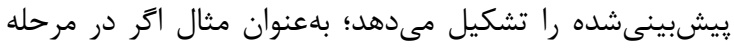

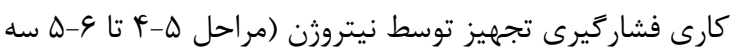

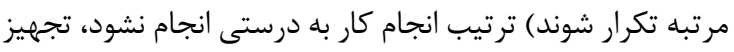

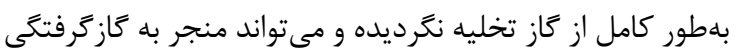
و يا مسموميت كاركران شود.

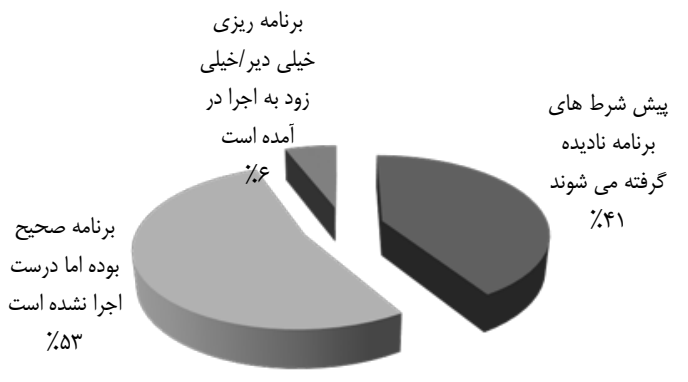

نمودار 9: خطاهاى برنامه ريزى

\section{بحث}

با توجه به نتايج بهدستآمده از اين يزوهش مشخص

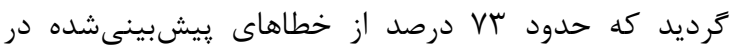

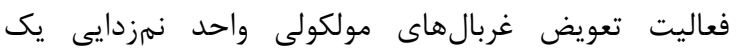

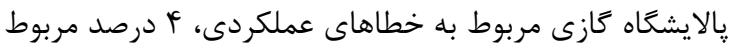

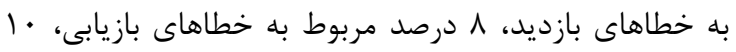

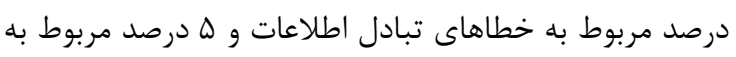

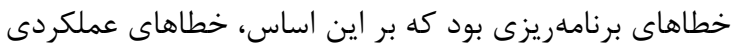

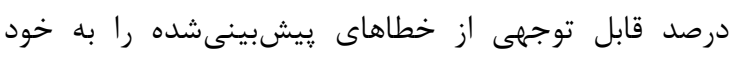

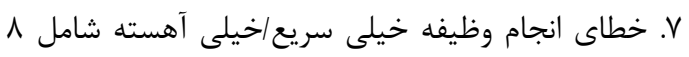
خطا؛ بهعنوان مثال در صورتى كه افزايش دما هنَعام انجام مرحله

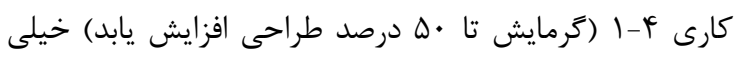

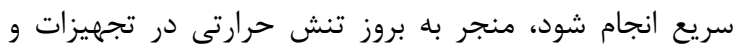

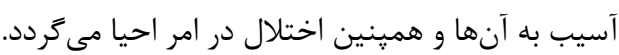

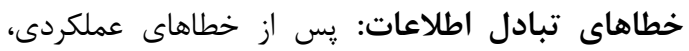

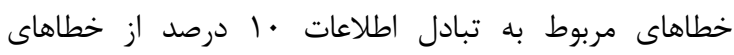

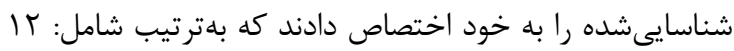

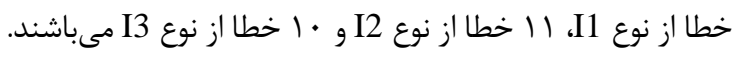
اين نوع خطا مىتواند به دليل بروز اشكال در تبادل اطلاعات بين

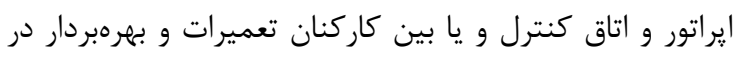

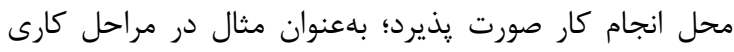

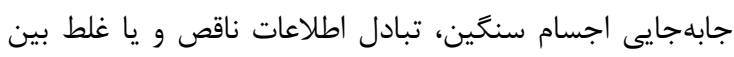

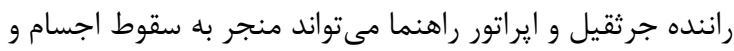
آسيب به تجهيزات و يا مرك فرد ترددد.

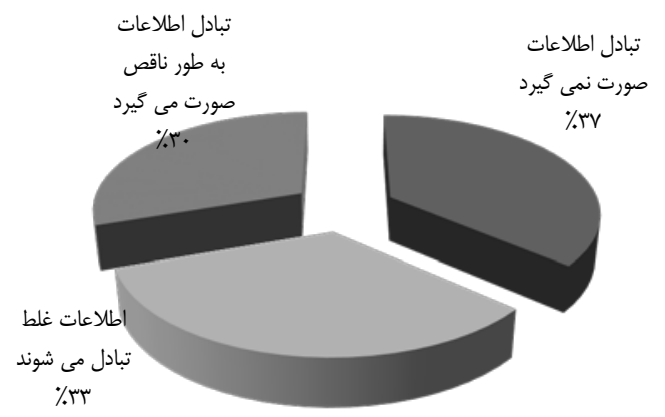

نمودار ץ: خطاهاى تبادل اطلاعات

خطاهاى بازيابى: خطاهاى شناسايىشده از نوع بازيابى

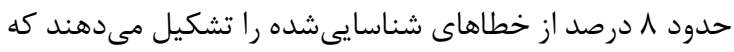

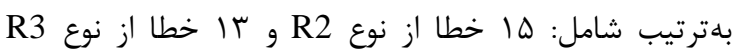
مىباشند. خطاهاى فوق ناشى از طراحى نامناسب و يا نقا نق در در

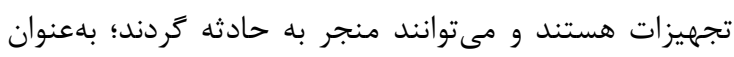

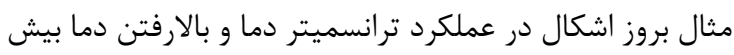

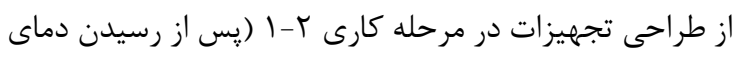

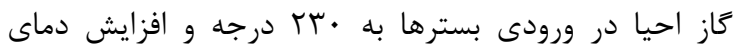

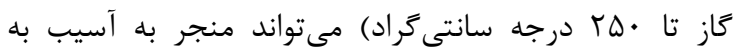

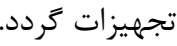

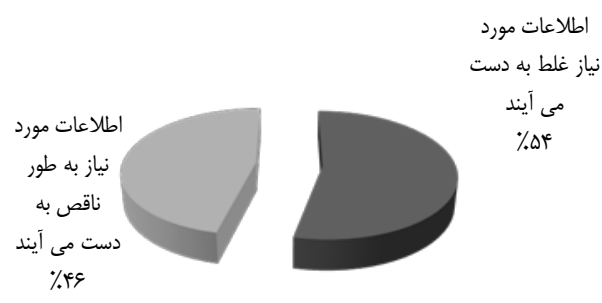

نمودار F: خطاهاى بازيابى 
خطاى انسانى مىشوند؛ بهعنوان مثال در مرحله كارى 1

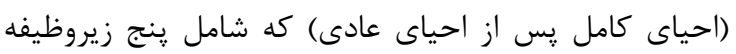

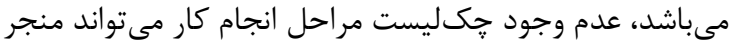

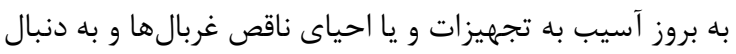

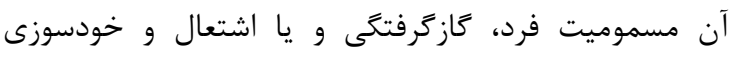

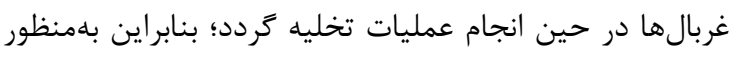
كاهش و يا جلوكيرى از بروز خطاهاى انسانى مرتبط بانيا

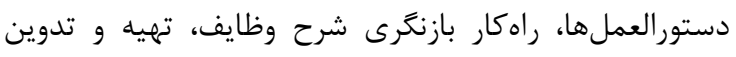

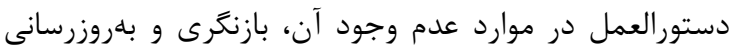
دستورالعمل هاى موجود همجون دستور العملهاى انجام ندام كارئ

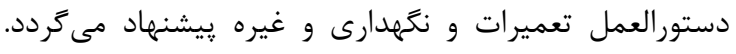

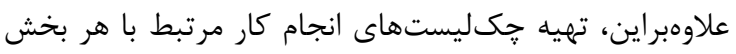

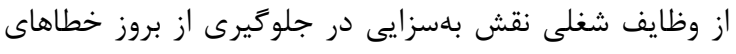

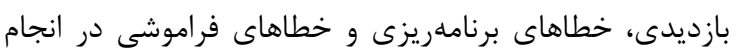

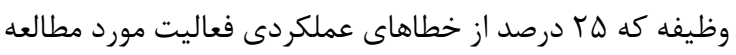
را تشكيل مى دهند، خواهد داشت. نظارت: نقش سريرست يا ناظر، كمك به موفقيت سيستم

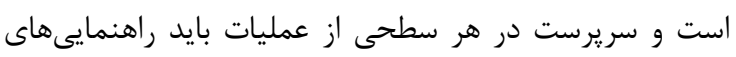

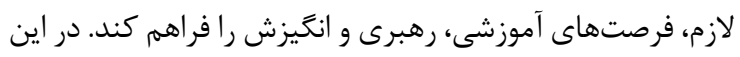

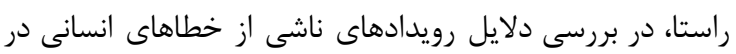

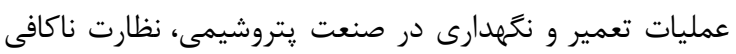

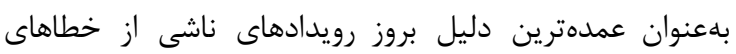

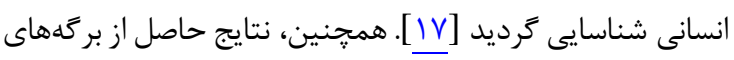

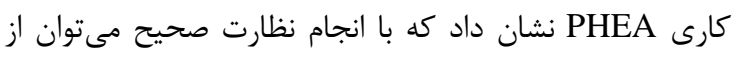

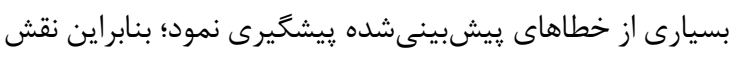

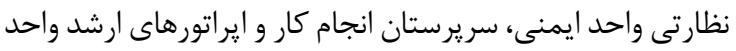

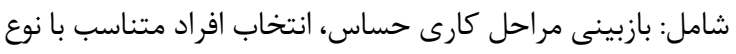

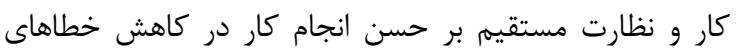

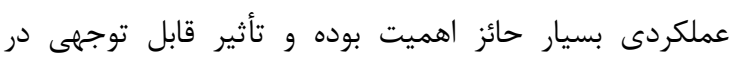
جلوكيرى از بروز حادثه دارد.

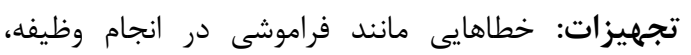

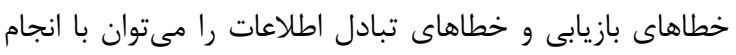

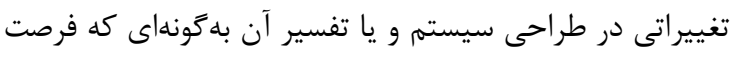

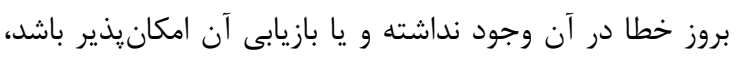

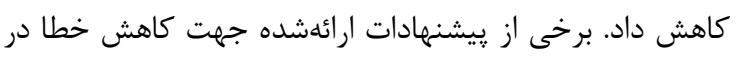

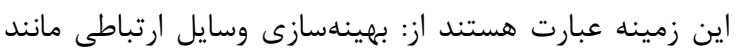

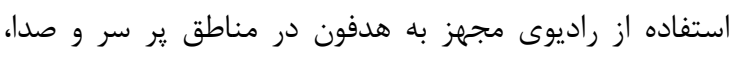

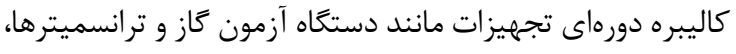

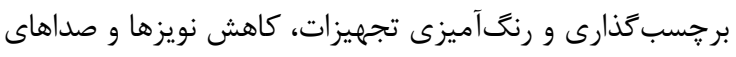

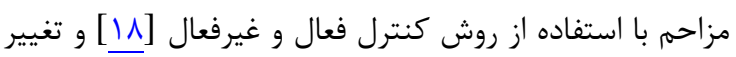

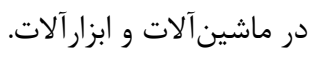

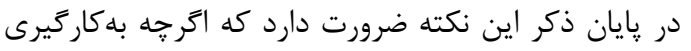

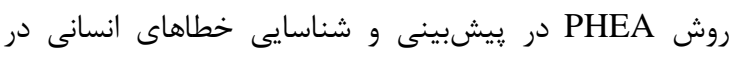

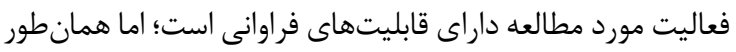

اختصاص دادهاند. با توجه به حوادث رخداده حين انجام

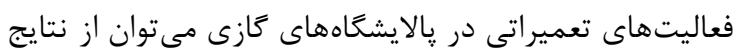

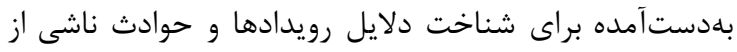

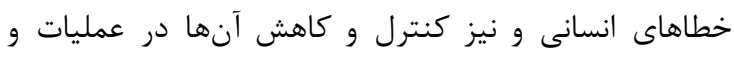

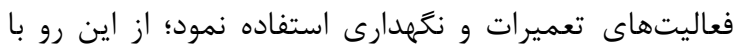
توجه به استفاده از روش

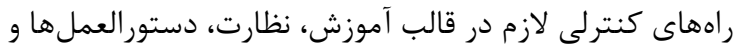

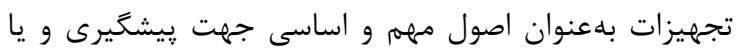
كاهش خطاهاى انسانى ارائه كَرديد.

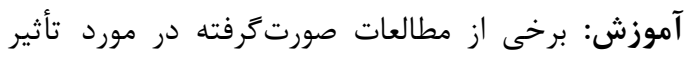

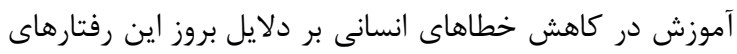

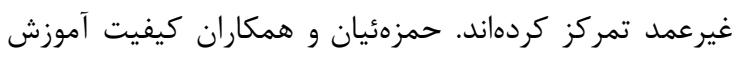

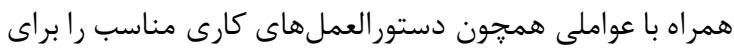

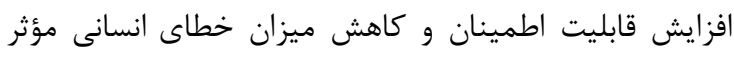

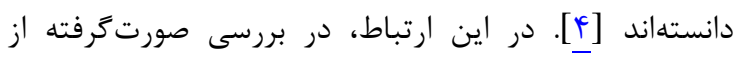

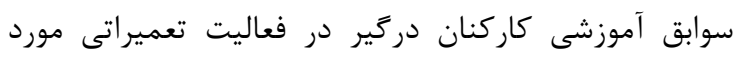

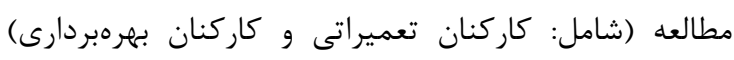

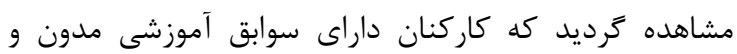

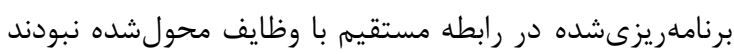

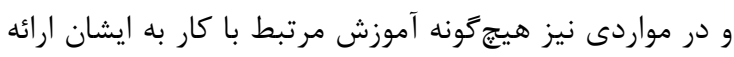

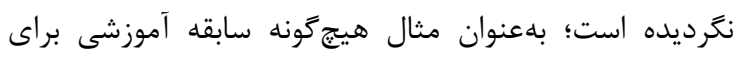

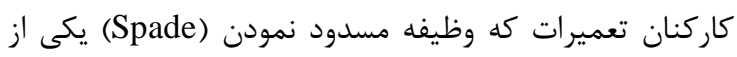

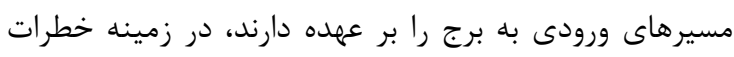

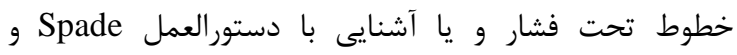

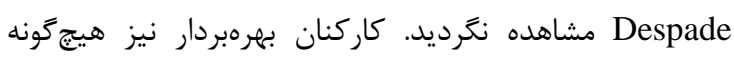

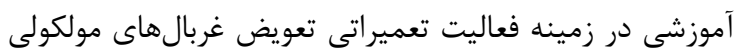

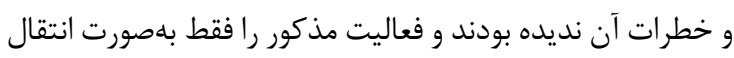

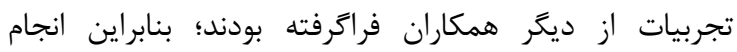

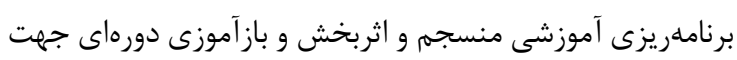

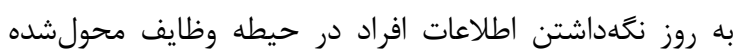

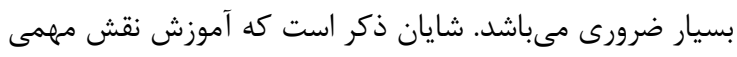

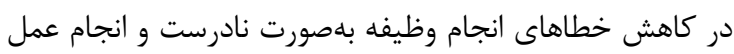

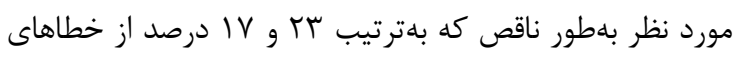
عملكردى فعاليت مورد مطالعه را تشكيل مى دهند، دارد.

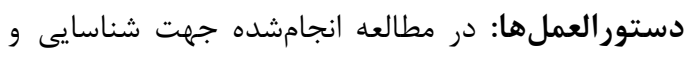

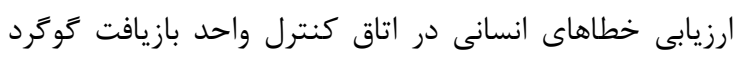

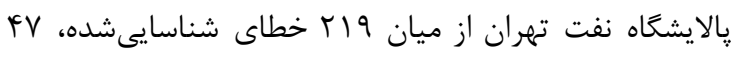

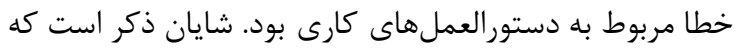

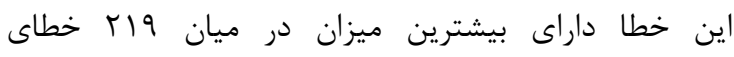

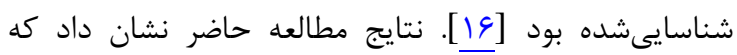

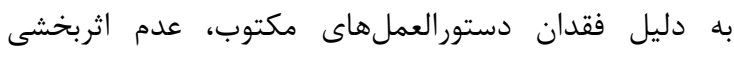

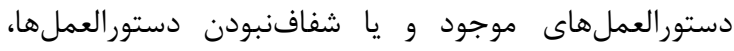

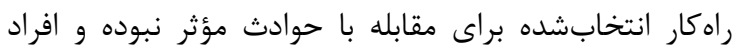

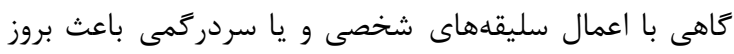




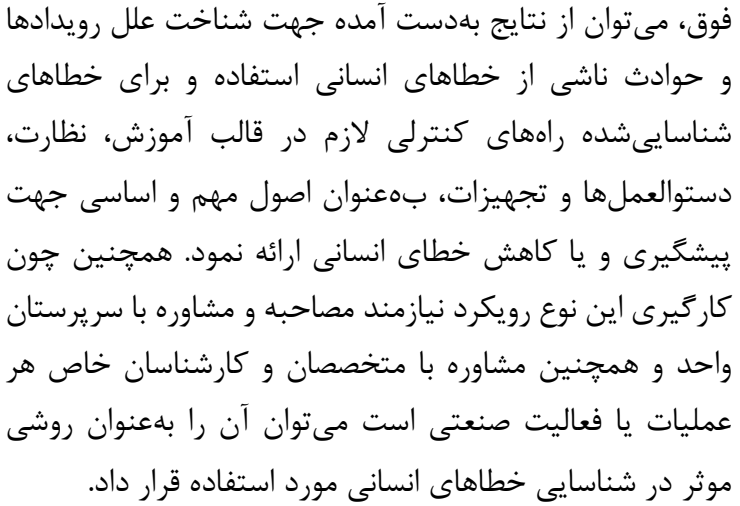
تشكر و قلروانى

بدينوسيله از استاديار زروه ايمنى صنعتى دانشعاه تابناك

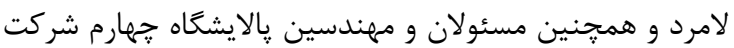

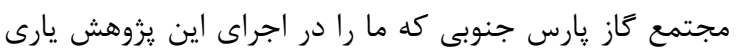
نمودند، صميمانه قدردانى مىشود.

\section{REFERENCES}

1. Heinrich HW. Industrial accident prevention: a scientific approach. New York: McGraw-Hill Book Company; 1931.

2. Christensen JM, Howard JM. Field experience in maintenance. In: Resmussen J, Rouse WB, editors. Human detection and diagnosis of system failures. New York: Springer; 1981. P. 111-33.

3. Johnson C. Why human error modelling has failed to help systems development. Oxford, UK: Oxford University Press; 1999. P. 517-24.

4. Hamzeian M, Mazloum A, Ziaee M, Jahangiri M. Relation of control methods and reliability. Seventh National Conference of Occupational Health, Ghazvin University of Medical Sciences, Ghazvin, Iran; 2011. [Persian]

5. Rastelli H, Shadden JS. Extending molecular sieve life in natural gas dehydration units. Gas Processors Association 86th Annual Convention Proceedings, San Antonio, Texas; 11-14 March 2007.

6. Danilczuk M, Dlugopolska K, Ruman T, Pogocki D. Molecular sieves in medicine. Mini Rev Med Chem. 2008;8(13):1407-17. DOI: 10.2174/138955708786369537

7. Baber C, Stanton NA. Human error identification techniques applied to public technology: predictions compared with observed use. Appl Ergon. 1996;27(2):119-31. PMID: $\underline{15677051}$

8. Hanafusa H, Mihama F, Iwaki T, Embrey D. Study on the methodology for predicting and preventing errors to improve reliability of maintenance task in nuclear power plant. INSS J. 2000;7:256-70.

9. Jahangiri M, Derisi FZ, Hobobi N. Predictive human error analysis in permit to work system in a petrochemical plant. Safety Reliabil. 2014;138:1007-10.

10. Adl J, Jahangiri M, Seraj J. Identification and analysis of

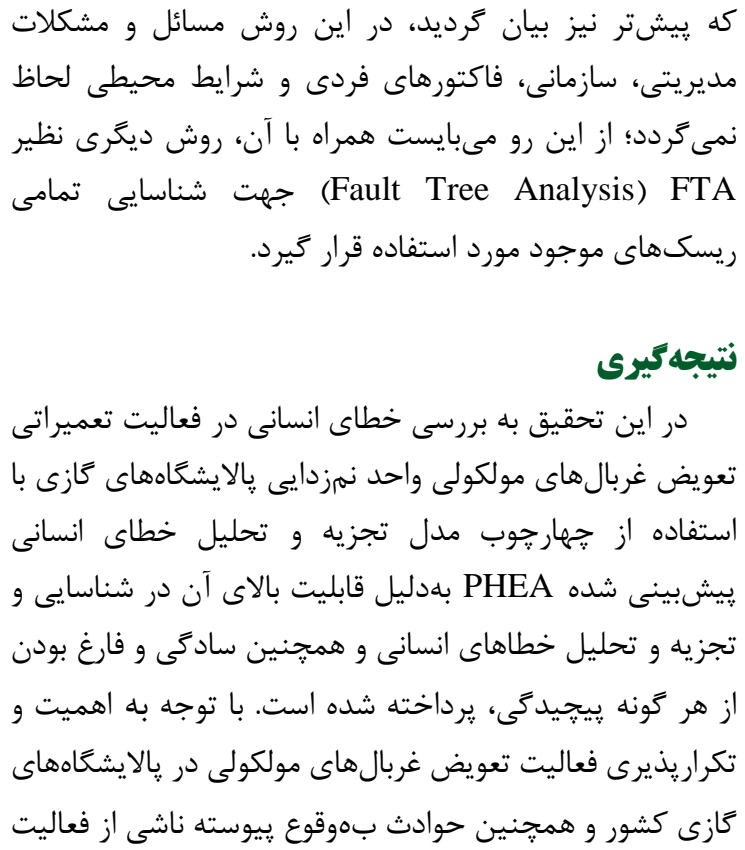

human errors by PHEA technique in isomax unit of an oil refinery. J Petroleum Res. 2005;52:54-62. [Persian]

11. Nezamodini ZA, Orosi M, Mombeini B. Assessment of human errors in paper machines of pars paper industrial group by Predictive Human Error Analysis (PHEA). Jundishapur J Health Sci. 2013;4(4):17-24. [Persian]

12. Movafagpour M, Nezamodini Z, Shirali GA. Prediction and analysis of human errors on the Boiler operator using PHEA method: A case study in dairy industry. Jentashapir J Health Res. 2013;4(5):339-44

13. Shepherd A. HTA as a framework for task analysis. Ergonomics. 1998;41(11):1537-52. DOI: 10.1080/001401398186063

14. Stanton NA. Hierarchical task analysis: developments, applications, and extensions. Appl Ergon. 2006;37(1):55-79. DOI: 10.1016/j.apergo.2005.06.003

15. Embrey DE. Quantitative and qualitative prediction of human error in safety assessments. Institution of Chemical Engineers Symposium Series. Philadelphia: Hemsphere Publishing Corporation; 1993. P. 329-50.

16. Mortazavi SB, Mahdavi S, Asilian H, Arghami S, Gholamnia R. Identification and assessment of human errors in srp unit of control room of tehran oil refinery using heist technique. $J$ Kermanshah Univ Med Sci. 2008;12(3):308-22. [Persian]

17. Azhdari MR, Monazzami Tehrani G, Alibabaei A. Investigating the causes of human error-induced incidents in the maintenance operations of petrochemical industry using human factors analysis and classification system. J Occup Hyg Eng. 2016;3(4):22-30. [Persian]

18. Rahmani O. Reduction of sound pollution by using active control method. The 2nd National Conference on Technology Development in Oil Industry, Tehran, Iran; 2004. [Persian] 